Open Access

\title{
The CAP 2013 reform of direct payments: redistributive effects and impacts on farm income concentration in Italy
}

\author{
Stefano Ciliberti ${ }^{*}$ and Angelo Frascarelli
}

\author{
* Correspondence: \\ stefano.ciliberti@unipg.it \\ Department of Agricultural, Food \\ and Environmental Sciences, \\ University of Perugia, Borgo XX \\ giugno, 74, 06122 Perugia, Italy
}

\begin{abstract}
The Common Agricultural Policy has traditionally provided support to farm incomes via direct payments under the Single Payment Scheme. This article analyzes whether the reform of the SPS will decrease the concentration of direct payments and evaluates the effect of the new direct payment scheme on the redistribution of farm incomes. The decomposition of the Gini coefficient allows analysis of the evolution of farm income and direct payment distributions in Italy from 2014 to 2020, and empirical results based on the Italian Farm Accountancy Data Network show that the CAP 2013 reform is expected to decrease the concentration of direct payments. However, the reform is also expected to limit the reduction in farm income inequality due to the adoption of a partial convergence model (the so-called "tunnel" model) instead of a total convergence model as well as, more generally, the increasing share of farm income that is dependent on increased market exposure, leading to higher risks of price volatility and increasing pressure on income.
\end{abstract}

Keywords: CAP, Gini coefficient, Direct payments, Farm income, FADN, Italy

\section{Background}

The introduction of the policy of decoupling direct payments (DPs) in the European Union (EU) coincided with an increase in uncertainty due to the greater volatility of global food prices and rising food security concerns, which negatively impact the stability of farm incomes (FIs). This uncertainty has led to calls to maintain agricultural supports, stimulate farm investments, and adopt productivity-enhancing modern technology (Rizov et al. 2013). Consequently, the debate over the Common Agricultural Policy (CAP) 2014-2020¹ began with the report "The CAP towards 2020," in which the EU attempted to respond to new economic, social, environmental, climate-related, and technological challenges.

Because agricultural and, increasingly, environmental interests traditionally dominate the development of the CAP, EU institutions have identified new objectives and policy instruments to improve the socio-economic condition of European farmers (Huang et al. 2010). First, the need to better target support, which would improve the quality of spending and remunerate farmers for the public goods that they provide, led to an innovative DP scheme designed to replace the Single Payment Scheme (SPS) (Westhoek et al. 2013). In addition, Regulation (EU) no. $1307 / 2013^{2}$ recognized a strong mandate

(c) The Author(s). 2018 Open Access This article is distributed under the terms of the Creative Commons Attribution 4.0 International License (http://creativecommons.org/licenses/by/4.0/), which permits unrestricted use, distribution, and reproduction in any medium, provided you give appropriate credit to the original author(s) and the source, provide a link to the Creative Commons license, and indicate if changes were made. 
for each Member State (MS) to manage many aspects related to DPs. In particular, the so-called "national flexibility" offered the opportunity to improve the consistency between national targets and policy decisions to improve the effectiveness of public resource spending (Erjavec et al. 2011; Grant 2010; van Ittersum et al. 2008; Westhoek et al. 2013).

In Italy, this task is particularly intricate for the national government because it must carefully manage the effects of the overall reduction of the ceilings for DPs (due to cuts to the Multiannual Financial Framework and the process of external convergence among MSs) and the impact of the internal convergence process. Specifically, policymakers have attempted to reconcile the need to balance the level of payments per hectare among administrative regions, altimetric regions, and agricultural sectors with increased requests for greater FIs in a sector where prices, income volatility, and natural risks are high and profitability levels are, on average, below those in the rest of the economy (Severini and Tantari 2013a).

As national decisions directly impact the redistribution of DPs and the profitability of many farms, the main objective of this paper is to analyze the impact of CAP 2013 reform on DPs and income distribution in Italy. From a methodological point of view, the main original and innovative contribution stems from the fact that previous attempts to evaluate the redistributive effect of DPs are mainly based on an ex-post approach (Keeney 2000; Severini and Tantari 2013a, 2013b and 2015); this paper also provides an ex-ante analysis based on a previous attempt to forecast the redistributive effect of the direct payments using the Gini coefficient $(G)$ included in the CAP 2020 Impact Assessment (European Commission 2011). Moreover, the impact of various scenarios of direct payments' regionalization was estimated ex-ante by scholars (see De Gocht et al. 2013 for all) and European institutions within the prospective studies of "Scenar 2020" (European Commission 2006, 2009). Both reports extensively analyze the distributive implications of various scenarios involving different levels of harmonization of decoupled payments.

The paper is organized as follows. The section "Methods" illustrates the theoretical framework related to the redistributive role of direct aids and describes the main elements of the direct payment reform in Italy. The section "Results and discussion" describes the methodology and data used to address the research questions. The section "Conclusions" presents the results and discusses them based on previous empirical evidence from Italy and the EU, then presents the conclusions.

\section{Literature review}

Farm subsidies were promoted due to concerns over the chronically low and highly variable incomes of farmers. The key stimulus for legislative action was the disparity between the incomes of farm and nonfarm households (Mishra and Paudel 2011), but ongoing pressures from World Trade Organization (WTO) negotiations, criticism of its trade-distorting effects, and consumer concerns regarding the safety and quality of agricultural goods have required the CAP to be continually reformed. In recent years, the most relevant innovation in terms of farm income support tools has been the introduction of decoupled payments by the EU, beginning with the CAP 2003 reform (Moro and Sckokai 2013), which has introduced a new direct payment architecture because 
the SPS has been replaced by an innovative system of DPs with eight components (three for mandatory and five for optional) (Westhoek et al. 2013).

Most direct payment instruments within the agricultural policy have at least the partial objective of income redistribution towards the neediest segments of the farming population (El Benni and Finger 2012). Therefore, to enhance the low average income level, agricultural policy must consider the income differences within the sector. The basis of such an approach is to define the overall redistributive effect of agricultural policy as the difference between the inequality of pre- and post support FIs; consequently, the aid cannot be considered equitable when the absolute level differs between farmers with a similar pre-support income. Maintaining a fair standard of living for the agricultural community and decreasing income disparities depend, indeed, on the distribution of direct aid among farmers. However, agricultural policies, at least those in developed countries, are rarely aligned with such basic ideals of distributional justice. The unequal distribution of economic benefits in the era of price support policies continues to function as an implicit benchmark of a "fair" distribution pattern; nevertheless, allocative policy objectives, which dominated at the beginning of the CAP, have been gradually replaced by distributional policy objectives in CAP reforms (Sinabell et al. 2013).

The OECD has identified equity as an operational criterion to evaluate agricultural policies. Indeed, a system of economically viable, midsized, owner-operated family farms contributes more to communities than do systems that are characterized by inequality, large numbers of farm laborers with below-average incomes, and minimal ownership or control of productive assets (Mishra et al. 2009). Howley (2016) asserted that despite their inefficient nature, these payments are indispensable for many farm operators since any elimination of decoupled payments would lead to a significant decline in asset values, which often constitute farmers' pension funds or their basis for future business expansion.

According to Mishra et al. (2009), farm income inequality impacts (1) economic well-being, including the health of farming families; (2) the adoption of farming technology; (3) agricultural productivity; and (4) growth in the agricultural sector. Consequently, if the purpose of farm policy is to raise the incomes of farmers and their standards of living, policy provisions must be reconsidered as changes occur in the farming business, considering that government payments play an important role in decreasing income inequality among farmers in certain regions. However, for many years, the European Commission has expressed concerns regarding the inequitable distribution of farm income support because DPs are highly concentrated (Allanson 2006), which supports the idea that large farms have been the main beneficiaries of CAP support. Consequently, the objective of guaranteeing income stability to reduce poverty and improve the quality of life of rural households is threatened. Eurostat data show that DPs are mainly provided to high-income farms, possibly because increasing the farm income is not the sole consideration that justifies the implementation of direct aid (Sinabell et al. 2013). The role played by agricultural policies in income distribution has been analyzed in various studies. Several studies conducted in Europe have shown that DPs decrease income inequality (Keeney 2000; Severini and Tantari 2013a, 2013b, 2015), but other studies have concluded that government payments increase income concentration (Allanson 2006; Schmid et al. 2006; El Benni and Finger, 2012). 
Von Witze and Noleppa (2007) highlighted that although small or medium farms should be the targets of DPs, the main beneficiaries of such payments are farms with large cultivated areas. The report on the distribution of direct payments for 2016, which thus includes choices made by MSs within the CAP 2013 reform, highlights that approximately $80 \%$ of direct payments are granted to approximately $20 \%$ of the largest beneficiaries (in terms of the amount of direct payments). This distribution is mainly driven by the concentration of land and the nature of the support, which is largely area-based. Direct payments are as concentrated as the productive area: 20\% of the largest farms in the EU concentrate $80 \%$ of the agricultural land and production (European Commission 2017). Moreover, decoupled direct payments linked to land positively influence land rents because only those who own or have rented eligible land can claim public support (Klaiber et al. 2017). Recent evidence confirms that the 2013 CAP reform caused land rental prices to increase relative to pre-reform conditions, and due to this effect, approximately 10.2 billion $€$ /year is expected to be channeled outside the farming sector in the EU in the 2014-2020 period. Such a leakage effect that benefits nonfarming landowners implies further income inequalities among farmers in the EU (Ciaian et al. 2017).

Schmid et al. (2006) claimed that, in most cases, DPs do not prevent a relevant share of European farmers from remaining in the poorest decile, and other authors (Allanson and Rocchi 2008; Mishra et al. 2009) confirmed that the distribution of direct aid is largely unequal because high-income farms receive a large share of the payments, as do the wealthiest farm households (Rocchi et al. 2005). Conversely, El Benni and Finger (2012) showed that direct aid can reduce the inequality in the distribution of FIs. Keeney (2000) stated that after the introduction of the McSharry reform, direct aid payments, although they were strongly concentrated, had a redistributive role in Ireland and were able to reduce the unequal effects on market incomes due to the increasing share of DPs in FIs. Thus, without DPs, the concentration of farm income and its unequal distribution across farms might have increased. In that context, the process of liberalizing global agricultural markets has led to an increasing share of farmers who generate negative market incomes, a situation that is unheard of in any other sector (El Benni and Finger 2012).

\section{Policy framework}

CAP 2013 reform increases flexibility for MSs, which implies the ability to implement the policy according to national needs. Consequently, the government must decide, above all, which optional payments to activate under the new direct payment scheme. The Italian budget for DPs in the 2015-2020 period varies from 3.9 to 3.7 billion $€ /$ year. The most important national choices made by the by Italian government are summarized in Table 1.

First, Italy extended the so-called "negative list" to include additional business activities that should be excluded from receiving DPs, and the government established certain criteria to identify active farmers (i.e., the beneficiaries of the new direct payment scheme), with flexible requirements for those in mountain areas and selective conditions for those in other areas. Nevertheless, regarding the minimum requirements for receiving DPs, Italy decided not to grant DPs to a farmer when the total amount of 
Table 1 Italian decisions on DPS

\begin{tabular}{|c|c|}
\hline Decision & National choice \\
\hline Active farmer (exemption threshold) & $<1250 €$ for other areas; $<5000 €$ for mountain areas \\
\hline Minimum requirements for receiving DPs & $<250 €$ DPs in 2015-2016; < $300 €$ DPs in 2017 \\
\hline Regional or national model/internal convergence & National/"tunnel" model \\
\hline Basic payment scheme (BPS) & $58 \%$ of national budget \\
\hline Redistributive payment & No \\
\hline Greening (amount of payment) & $\begin{array}{l}30 \% \text { of national budget (calculated as } 30 \% \text { of payment } \\
\text { entitlements held by the farmer) }\end{array}$ \\
\hline Areas that have natural constraints & No \\
\hline Young farmers payment (YFP) & $\begin{array}{l}1 \% \text { of national budget (value: } 25 \% \text { of the average value } \\
\text { of payment entitlements) }\end{array}$ \\
\hline Voluntary coupled support (VCS) & $\begin{array}{l}11 \% \text { of national budget (of which } 25.1 \% \text { is for beef, } 20.8 \% \\
\text { for milk, } 16.4 \% \text { for olive oil, } 14 \% \text { for cereals, } 8.3 \% \text { for protein } \\
\text { crops, } 5.3 \% \text { for rice, } 4 \% \text { for sugar beet, } 3.5 \text { for sheep, } 2.6 \% \\
\text { for industrial tomato production) }\end{array}$ \\
\hline Small farmers scheme (max. payment) & Yes $(<1250 €)$ \\
\hline Degressivity and capping (\% reduction in DPs) & $\begin{array}{l}50 \% \text { if dir. paym. }>150 \mathrm{M} € ; 100 \% \text { if dir. paym. }>500 \mathrm{M} € \text {; } \\
\text { salary costs deducted }\end{array}$ \\
\hline
\end{tabular}

Source: Ciliberti and Frascarelli (2015)

payments claimed is less than $250 €$ (regardless of farm size) in 2015-2016 and less than $300 €$ after 2017.

More interestingly, the Italian government decided to apply the so-called "tunnel" model (TM) for internal convergence instead of the flat rate. This latter model leads to a uniform value of payment entitlements by 2019 (217.64 $€ /$ ha). In the tunnel model $\mathrm{TM}$, the mechanism for establishing the values of entitlements depends on two main parameters: the initial unit value (IUV) of payment entitlements and the national unit value (NUV). In 2019, the latter can be simply determined with the following formula:

$$
(X / Y) \times(P / R)
$$

where $X$ is the national ceiling for the basic payment scheme (BPS) for the year 2015, $Y$ is the national ceiling for 2015, $P$ is the national ceiling for the BPS for calendar year 2019 , and $R$ is the number of allocated payment entitlements in 2015, excluding those allocated from the national reserve.

The value of the payment entitlements that the farmers will receive during 20152020 will depend on the IUV, which in turn can be established as follows:

$$
(x / y) \times(A / B)
$$

where $x$ is the national ceiling for the BPS for the year 2015, $y$ is the amount of the payments for 2014 under the SPS in the MS, $A$ is the payments that the farmer received for 2014, and $B$ is the number of payment entitlements that the farmer is allocated in 2015.

In practice, the "value" that is carried forward from 2014 is spread across the "number" of entitlements allocated to the farmer in 2015. This IUV forms the basis of all subsequent convergence calculations for the value of those entitlements for each year of the scheme. All entitlements held under the BPS are subject to convergence effects (Fig. 1). 


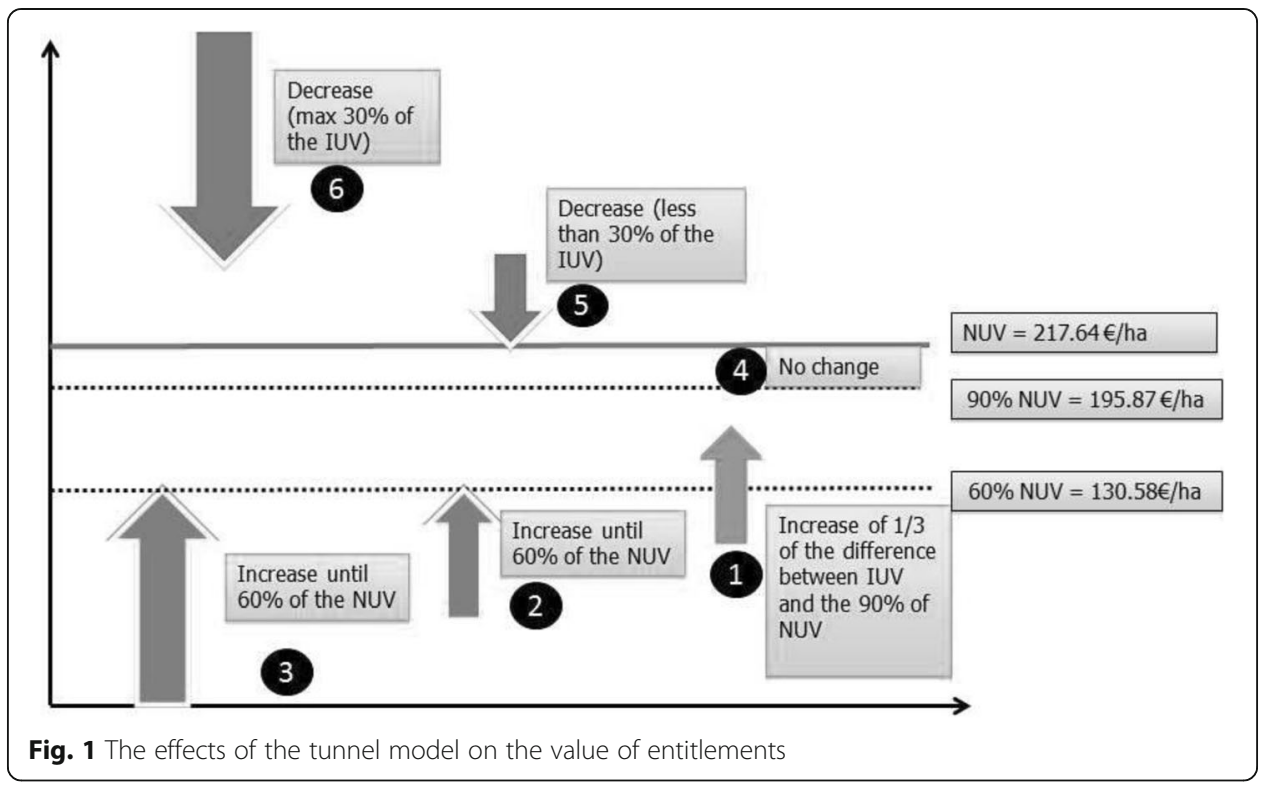

In simple terms, those who hold entitlements with an IUV greater than the national average under the BPS will see the value of their entitlements decrease over the 5 years of the scheme, whereas those with entitlements that have an IUV below $90 \%$ of the national average will see the value of their entitlements gradually increase. Those who hold entitlements that have an IUV between 90 and 100\% of the national average value will see no change. In addition to the standard level of convergence outlined above, a further test is applied whereby all farmers must achieve a minimum entitlement value of $60 \%$ of the national average by 2019 . If a farmer does not reach this level under the standard convergence, the value of his entitlements will be increased in equal steps to ensure that it is achieved by 2019. Moreover, the change introduces a "stop-loss mechanism" that reduces losses (no more than 30\% of their initial value in 2015) for high entitlement payments.

Furthermore, the allocation of national resources across the seven components of direct payments was as follows: the BPS received 58\% of resources, greening payment (GR) received 30\% of the budget (as established by Reg. 1307/2013), the young farmer payments (YFPs) received $1 \%$ of national funds, the voluntary coupled support (VCS) received $11 \%$ of funding, and the small farmers scheme (SFS) was activated. It must be noted that even though the GR refers to environmental concerns, the value of this payment in Italy depends on the value of the BPS (due to the application of the tunnel model of internal convergence, i.e., partial convergence of entitlement values). Therefore, since this aid varies based on the value of the entitlements associated with the land, its redistributive effect on farm income must be properly considered. Lastly, the redistributive payment and payment for areas with natural constraints were not activated. Other decisions are reported in Table 1.

\section{Methods}

Against this policy and theoretical background and due to the growing public interest in the effects of the CAP on income distribution in the agricultural sector, this paper aims to test the following research hypotheses with a specific focus on Italy: 
H1: The application of CAP 2013 reform in Italy causes a decrease in the unequal concentration of DPs.

H2: the application of CAP 2013 reform in Italy improves the redistributive role of DPs.

H3: the application of the tunnel model in Italy, compared to the flat rate, limits the redistribution of the DPs and their equalizing effect on farm income.

The methods and data adopted to address the research questions are presented in this section.

\section{The decomposition of the Gini coefficient: static and dynamic analyses}

In income inequality research, the Gini coefficient $(G)$ is a commonly used measure of relative income inequality that ranges between 0 and 1 . If farm income is equally distributed (i.e., all farms have the same income), the $G$ value is 0 ; with greater income inequality, $G$ approaches 1 (i.e., a single farm generates the entire income of the population). To estimate $G$, the income $Y$ is assumed to be a random variable distributed with mean $\mu$ across the farm population. With $F(Y)$ being the cumulative distribution function of income (ranked in nondecreasing order) and cov being a covariance indicator, $G$ can be written as follows (El Benni and Finger 2012; Mishra et al. 2009):

$$
G=2 \operatorname{cov} \frac{[Y, F(Y)]}{\mu}
$$

Many studies have formulated $G$ decomposition schemes and relative measures that capture the impact of various components of income on inequality (Lerman and Yitzhaki 1985; Pyatt et al. 1980). Specifically, the decomposition of $G$ by a component of farm income (e.g., market income and DPs) has been frequently applied in the economics literature to measure the effect of different income sources on aggregated income inequality (El Benni and Finger 2012; Severini and Tantari 2013a, 2013b, 2015; Keeney 2000; Lerman and Yitzhaki 1985).

In practical terms, the static analysis of the decomposition of $G$ aims to analyze the total income concentration as the sum of the income concentration from $k$ different sources, $Y_{k}$, with $F\left(Y_{k}\right)$ denoting the cumulative distribution function of the income source under consideration. Therefore, the decomposed $G^{3}$ can be written as follows:

$$
\begin{aligned}
G & =\sum_{k=1}^{k} \frac{\operatorname{cov}[Y k, F(Y)]}{\operatorname{cov}[Y k, F(Y k)]} \times \frac{2 \operatorname{cov}[Y k, F(Y k)]}{\mu k} \times \frac{\mu}{\mu k}=\sum_{k=1}^{K} R k \times G k \times S k \\
& =\sum_{k=1}^{K} C k \times S k
\end{aligned}
$$

The Gini correlation coefficient, $R_{k}$, ranges between -1 and +1 ; if the income of the $k$ th income source increases (decreases) with increasing total income, $R_{k}$ is positive (negative), and if $R_{k}$ equals 0 , the income source is a constant that does not contribute to total income inequality. $G_{k}$ is the $G$ of the $k$ th income source and shows how the income from the specific income source is distributed within the population. $S_{k}$ is the share of the $k$ th income source of the total income. The product of $R_{k}$ and $G_{k}$ yields the concentration coefficient (or pseudo-G) of the $k$ th income source $\left(C_{k}\right)$, which measures how the income from each source is transferred across a population ranked with 
respect to the level of total income received. $C_{k}$ is 0 if all income groups receive an equal amount of income from the given income component, is negative if the income from a specific source mainly accrues to the farms in the lower tail of the total income distribution, and is positive if richer households receive a large proportion of the income from the specific income component. In addition, a $C_{k}$ that is larger than the $G$ of the aggregate income proves that the income component in question has an unequalizing effect on the observed aggregate income distributions (El Benni and Finger 2012; Keeney 2000). Furthermore, Pyatt et al. (1980) and Lerman and Yitzhaki (1985) developed a measurement that partitions the overall inequality of a particular distribution into contributing components. This measurement, in the case of income, explains the proportional contribution to inequality $\left(P_{k}\right)$ by the $k$ th income source:

$$
P k=\frac{R k \times G k \times S k}{G}
$$

To evaluate the marginal impact of a single income component on income inequality, Lerman and Yitzhaki (1985) derived a measure of the rate of change in $G$ with respect to the mean of the $k$ th income component, from which it is possible to derive the elasticity $\left(\eta_{k}\right)$ of $G$ with respect to changes in the income components as follows:

$$
\eta_{k}=\frac{u_{k}}{G} \times \frac{d G}{d u_{k}}=\frac{1}{G} \times\left[\frac{u_{k}}{\mu} \times\left(C_{k}-G\right)\right]
$$

This calculation allows the impact of a $1 \%$ change in a single income source on the income concentration to be measured. Specifically, $\eta_{k}$ is greater (less) than 1 if the amounts received under the specific income component increase more (less) than is proportional to the total income. In the case of unit elasticity, the distribution of income from a particular source is proportional to the distribution of total income; thus, the concentration coefficient and $G$ coincide (Keeney 2000; Podder and Chatterjee 1998).

The dynamic analysis implemented by Keeney (2000) is instead conducted based on the specification of Podder and Chatterjee (1998) to consider the contribution of a change in overall inequality due to the change in the components of income over time. Therefore, the change in $G$ over time is approximately divided into a share effect (SE) and a concentration effect (CE):

$$
\Delta G_{t} \approx S E+C E
$$

The change in the aggregated $\mathrm{G}$ from period $t-1$ to $t$ is given by $\Delta G_{t}=G_{t}-G_{t-1}$. Changes in $G$ can be attributed to a change in the share of the $k$ th income component of the total income, $\Delta S_{k, t}=S_{k, t}-S_{k, t-1}$, and to the change in the concentration coefficient between period $t-1$ and $t$, namely, $\Delta C_{k, t}=C_{k, t}-C_{k, t-1}$. In practice, the SE shows how a change in the share of a specific income component affects the change in the overall Gini. In contrast, the CE shows how a change in the distribution of source incomes over the ranges of total income affects the change in $G$. In sum, the approximation of the total derivative of the $G$ with respect to time is

$$
\Delta G_{t} \approx \sum_{k=1}^{K} C k, t \times \Delta S_{k, t}+\sum_{k=1}^{K} S k, t \times \Delta C_{k, t}
$$

where the first summation group represents the part of the change due to the SE, and the second summation group represents the part of the change due to the CE. 
Data

Four static analyses of the disaggregation of the Gini coefficient were performed. Weighted data from the Farm Accountancy Data Network (FADN) database for the years 2014 and 2015 were used to conduct the analyses (European Commission 2010). Therefore, samples from 2014 and 2015 consisting of 10,488 and 9134 farms, respectively, were reported to the universe ${ }^{4}$ (Table 2). Moreover, using weighted data allows possible bias due to the comparison between unbalanced samples to be greatly reduced. Lastly, it must be noted that the presence of farms with negative incomes does not affect the reliability and the accuracy of the Gini coefficient, since the average income of the sample is positive (Findeis and Reddy 1987; Pyatt et al. 1980).

The following variables are taken into account for the empirical analyses:

- The farm income (FI), which is the remuneration for the fixed factors of production of the farm and the remuneration for the entrepreneurs' risks (loss/profit) in the accounting year

- Farm net value added (FNVA), which is the remuneration for the fixed factors of production (work, land and capital), whether they be external or family factors

- Total output (TO), which represents the total of the output of crops and crop products, livestock and livestock products, and other outputs

- Work unit (WU), which is the total labor input expressed as full-time person equivalent

- Utilized agricultural area (UAA), which is the total area taken up by arable land, permanent pastures and meadows, land used for permanent crops, and kitchen gardens

In detail, two static analyses were conducted for 2014 (CAP Health Check) and 2015 (CAP 2013 reform). Subsequently, the remaining static analyses were conducted for 2019 (the first implementing the tunnel model and the other simulating the flat rate). These latter analyses were based on simulations run by inserting and adapting the FADN 2015 database in a specific software ${ }^{5}$ that rigorously considers all the technical

Table 2 Characteristics of the FADN samples

\begin{tabular}{|c|c|c|c|c|c|}
\hline & & \multicolumn{2}{|l|}{2014} & \multicolumn{2}{|l|}{2015} \\
\hline & & Sample & Weighted sample & Sample & Weighted sample \\
\hline \multirow[t]{3}{*}{ Geographic area } & Northern IT & 42.8 & 25.3 & 42.5 & 29.7 \\
\hline & Central IT & 19.1 & 21.8 & 17.8 & 17.7 \\
\hline & Southern IT & 38.1 & 52.8 & 39.7 & 52.6 \\
\hline \multirow[t]{3}{*}{ Altimetric zones } & Mountain & 21.5 & 16.5 & 22.1 & 17.1 \\
\hline & Hill & 45.5 & 58.0 & 46.1 & 51.6 \\
\hline & Plain & 33.0 & 25.5 & 31.8 & 31.3 \\
\hline \multirow[t]{5}{*}{ Economic size } & Small (4-25 k€) & 24.5 & 36.0 & 24.0 & 44.5 \\
\hline & Small-medium (25-50 k€) & 21.5 & 31.4 & 22.9 & 20.9 \\
\hline & Medium (50-100 k€) & 25.8 & 4.6 & 23.8 & 12.4 \\
\hline & Medium-large (100-500 k€) & 21.6 & 21.7 & 22.1 & 18.4 \\
\hline & Large (> $500 \mathrm{k} €)$ & 6.6 & 6.2 & 7.2 & 3.8 \\
\hline
\end{tabular}


mechanisms established by Reg. (EU) 1307/2013 and the Italian decisions described above.

To simulate DPs for 2019 (under tunnel model and flat rate), some calculations were made based on FADN 2015 data to find the IUV and the NUV.

For the flat rate, a fixed amount of BPS (equal to the NUV, that is, $217.64 € /$ ha) is assigned to all hectares of the FADN15 database. Then, GR and YFP are calculated as percentages (50 and 25\%, respectively) of the BPS, while VCS and SFS are maintained at the 2015 level.

For the tunnel model, the IUV must be calculated to simulate the amount of DPs (starting from BPS) for 2019. This value is obtained by applying the following formulas depending on the relationship between BP15/ha and NUV:

$$
\begin{aligned}
& I U V=(5 \times B P S 15-0.3 \times N U V) / 4.7, \text { if BPS15 }>N U V ; \text { or } \\
& I U V=(15 B P S 15-N U V) / 14, \text { if } 107.5<B P S 15<0.9 N U V .
\end{aligned}
$$

Furthermore, two other cases (and two identities) enable the completion of the DP simulation (starting from BPS) under the tunnel model in 2019:

$$
\begin{aligned}
& B P S 2019=145.6, \text { if } B P S 15<107.5 ; \text { or } \\
& B P S 19=B P S 15, \text { if } 0.9 N U V<B P S 15<N U V .
\end{aligned}
$$

Therefore, the abovementioned software was used to simulate the impact of CAP reform on DPs in 2019 under both the tunnel model and the flat rate.

In greater detail, both simulated models have the following characteristics:

- The models are static, meaning that crop adaptation to income support policies (e.g., cross compliance and greening) is not considered. More generally, any behavioral model that predicts changes induced by the new structure of the payments is implemented, but the adaptation strategies of farmers are not taken into account. Since the dataset used for the ex-ante analysis for 2019 is obtained from the first year of implementation of the CAP 2013 reform (2015), the changes induced by the new DP structure (such as voluntary coupled support and greening that may affect choices in terms of crop mix or the scale of livestock activities) are already contained in the FADN dataset for 2015.

- Three of the five DP components activated in Italy for the period scheme are simulated by the software; these components are BPS, GR, and YFP, which account for approximately 90\% of the Italian ceiling on DPs in 2019.

- The BPS for 2019 accounts for the effect of degressivity and capping. ${ }^{6}$

- The VCS and the SFS, which account for the remaining 10\% of the Italian ceiling on DPs in 2019, are also considered, but they are maintained at the 2015 level because, based on previous experience, it is likely that (i) nearly all farms that received the VCS and SFS in 2015 will receive them in 2019, and (ii) the level of payment should not change significantly over time.

According to Keeney (2000), the considered income parameter is farm income, which is composed of two main components: market-based income (MI) and DPs. The former is calculated by subtracting the amount of the DPs from the farm income; DPs are 
identified by considering only the annual payments granted to farmers in the context of the market and income support policies. These payments are split into two components: the SPS (for 2014) or "BPS + GR + YFP + SFS" (for 2015 and 2019), which are both based on the ownership of payment entitlements and the VCS.

The main limitation of the study is that the methods adopted are static and thus do not take adaptive strategies of farmers into account. Moreover, simulations for 2019 are based on 2015 farm income levels, and the software cannot foresee the evolution of other variables (prices, yields, and so on) that affect farm income.

In addition, the 2019 analyses are based on simulations that do not consider the same budget for DPs due to the forecasted reduction between 2015 and 2019. In detail, these simulations consider only three of the five new DP components (accounting for approximately of $90 \%$ of the Italian budget) since VCS and SFS are maintained at the same level as in 2015. With respect to the level of BPS for 2019, NUV and IUV are derived from the FADN 2015 database by accounting for the real number of entitlement payments for 2015, whereas the greening payment for 2019 is assigned to all farms (supposing that they all fulfill the three greening commitments). The YFP for 2019 is assigned to the same farms that received this aid in 2015, assuming that all the young farmers started their activities in 2015 and will thus benefit from this payment for 5 years. Furthermore, the simulations obviously cannot account for new entries as well as exits from the agricultural sector in 2019 because they are unpredictable.

\section{Results and discussion}

The results show the evolution of income distribution over the time due to the reduction in the concentration of income. The main aim is to verify whether and how the implementation of CAP 2013 reform in Italy changed how DPs affect the distribution of income. In detail, special emphasis is placed on DPs because, for the first time in the long history of the CAP, their configuration has been strongly affected by national decisions.

Table 3 reports correlations between the DPs and the following variables that were previously described in the methodology section for 2014-2015. Indeed, it is not surprising that DPs are correlated with land (UAA), but this fact has specific implications. The choice of land as an allocation parameter makes the DPs more closely correlated with UAA than with farm income. Furthermore, the results show that DPs are much more correlated with UAA than WU.

Table 3 Correlation matrix

\begin{tabular}{lllllll}
\hline & FI & FNVA & TO & WU & UAA & DPs \\
\hline FI & 1.000 & & & & & \\
FNVA & 0.966 & 1.000 & & & & \\
TO & 0.860 & 0.889 & 1.000 & & & \\
WU & 0.471 & 0.610 & 0.524 & 1.000 & & \\
UAA & 0.436 & 0.479 & 0.457 & 0.391 & 1.000 & \\
DPs & 0.376 & 0.392 & 0.432 & 0.246 & 0.394 & 1.000 \\
\hline
\end{tabular}

Source: own elaboration on FADN 2014 and 2015 
Farm income inequality can be preliminarily explored by ranking farms by FI levels for 2014-2015 and dividing them into decile groups (Table 4).

This process allows an initial evaluation of the extent of income disparity: the farms belonging to the top two deciles always received approximately $80 \%$ of the entire farm income, but they absorbed slightly more than $45 \%$ of work unit and UAA. DPs are also strongly concentrated across the farms in the uppermost deciles, since $70 \%$ of direct aid goes to farms in the top three deciles. Conversely, although they employed approximately $25 \%$ of work unit and farmed $15 \%$ of the UAA, farms under the median value produced a very small share of the farm income, and of particular interest, they received less than 15\% of the DPs in 2014-2015.

\section{Static and dynamic analyses}

In this section, empirical results of the decomposition of the Gini coefficient of farm income are reported according to the above-defined research hypotheses.

Table 5 reveals the distribution of the DPs and farm income in the transition period between the last year of implementation of the CAP Health Check (2014) and the first year of the application of the CAP 2013 reform (2015).

The results show that farm income is highly concentrated in both years, although the concentration decreases between years $\left(G_{\mathrm{FI} 14}=0.818\right.$ and $\left.G_{\mathrm{F} 115}=0.778\right)$; this evidence is in accordance with previous studies (Severini and Tantari 2013a, 2013b, 2015). $G_{\mathrm{FI}}$ is also higher than that reported by Keeney (2000) for Ireland in the 1990s, by El Benni and Finger (2012) for Switzerland and by Allanson (2006) for Scotland in the last decade, but it is smaller than for the US.

Furthermore, the relative importance $\left(S_{k}\right)$ of the three considered income components is not homogeneous because market-based income represents between 88 and 93.5\% of the total income of the farm in the observed period, whereas the DPs amount to $12 \%$ of the farm income in 2014 and $6.5 \%$ in $2015 .{ }^{7}$ Such an outcome cannot be attributed only to the reduction of the national ceiling for DPs but is strongly influenced by the changes in market conditions. Specifically, market-based income strongly affects unequal income distribution since it is strongly concentrated in the uppermost deciles of the farm population $\left(C_{\mathrm{MI14}}=0.864\right.$ and $\left.C_{\mathrm{MI15}}=0.796\right)$. It follows that the relative

Table 4 Distribution of FI, FNVA, TO, WU, UAA, and DPs by deciles of FI classes, \% of the sample

\begin{tabular}{lllllll}
\hline Decile group & $\mathrm{Fl}$ & FNVA & TO & WU & UAA & DPs \\
\hline 1 & -1.9 & 1.3 & 3.7 & 6.6 & 4.9 & 4.6 \\
2 & 0.3 & 0.5 & 0.7 & 2.3 & 1.4 & 1.5 \\
3 & 0.7 & 1.0 & 1.3 & 3.6 & 2.1 & 2.1 \\
4 & 1.4 & 1.9 & 2.0 & 4.8 & 3.0 & 3.1 \\
5 & 2.2 & 2.7 & 2.8 & 6.1 & 4.5 & 4.6 \\
6 & 3.5 & 4.0 & 3.9 & 7.3 & 6.3 & 5.9 \\
7 & 5.5 & 5.9 & 5.6 & 9.2 & 8.9 & 7.9 \\
8 & 8.7 & 8.9 & 8.4 & 11.5 & 12.0 & 10.6 \\
9 & 15.6 & 15.4 & 14.7 & 15.7 & 18.9 & 16.7 \\
10 & 64.0 & 58.4 & 56.9 & 32.9 & 38.0 & 43.1 \\
\hline Source: own elaboration on FADN 2014 and 2015 & & & &
\end{tabular}

Source: own elaboration on FADN 2014 and 2015 
Table 5 Gini decomposition of total income. Static analyses (2014 vs 2015)

\begin{tabular}{ccccccc}
\hline & $G_{k}$ & $R_{k}$ & $S_{k}$ & $C_{k}$ & $P_{k}$ & $\eta$ \\
\hline 2014 & & & & & & \\
$\mathrm{FI}$ & 0.818 & 1.000 & 1.000 & 0.818 & 1.000 & 0.000 \\
$\mathrm{MI}$ & 0.874 & 0.988 & 0.879 & 0.864 & 0.928 & 0.049 \\
$\mathrm{VCS}$ & 0.927 & 0.642 & 0.011 & 0.595 & 0.008 & -0.003 \\
SPS & 0.731 & 0.648 & 0.110 & 0.474 & 0.064 & -0.046 \\
2015 & & & & & & \\
$\mathrm{FI}$ & 0.778 & 1.000 & 1.000 & 0.778 & 1.000 & 0.000 \\
$\mathrm{MI}$ & 0.798 & 0.997 & 0.935 & 0.796 & 0.957 & 0.022 \\
$\mathrm{VCS}$ & 0.862 & 0.680 & 0.006 & 0.586 & 0.005 & -0.002 \\
BPS + SFS + GR + YFP & 0.711 & 0.710 & 0.058 & 0.505 & 0.038 & -0.020 \\
\hline
\end{tabular}

Source: own elaboration

contribution of market-based income to inequality is very high, as shown by the fact that it generated more than $90 \%$ of the overall income inequality in 2014$2015\left(P_{\mathrm{MI} 14}=0.928\right.$ and $\left.P_{\mathrm{MI1}}=0.957\right)$.

With respect to H1 (the application of CAP 2013 reform in Italy causes a decrease in the unequal concentration of DPs), the decomposition of $G$ shows that the new direct payment scheme in Italy decreases the concentration of DPs and leads to a more equal redistribution of DPs in 2019 (although this effect is still not evident in 2015). In particular, this effect is due to the implementation of the tunnel model for internal convergence, which bridges the gap in the value of entitlements across Italian farms and makes them progressively less dependent on the rank of farm income. According to Severini and Tantari (2013b), any change in the distribution of DPs among farms could bring about a change in farm income concentration. This situation clearly holds for area redistribution and coupled payments generated by shifting from the individual farm-based (i.e., historical) model to the national flat rate model of direct aid implementation. It follows that the flat rate allows a redistribution of DPs that indeed penalizes sectors that have a high farm income but are largely dependent on DPs (a high DP/FI ratio), whereas it increases the share of direct aid for sectors that traditionally do not benefit from such support (vineyards, fruits, and vegetables) and for low-income sectors that are located in disadvantaged areas (livestock and grazing).

Regarding H2 (the application of CAP 2013 reform in Italy improves the redistributive role of DPs), Table 5 highlights that both area and coupled payments decrease their proportional contribution to inequality due to the CAP 2013 reform. However, the marginal impact of area payments on income inequality declines between 2014 and 2015, whereas it is expected to increase smoothly towards 2019. The dynamic analysis (Table 6) reveals that such an impact may also be attributable to the decrease in the relevance of DPs to farm income from 2015 onwards, which both reduces the ability to offset the unequal redistributive effect of the market-based income and limits the redistributive and stabilizing effect of DPs on farm income (Severini and Tantari 2013a; 2016).

Table 6 Dynamic analysis: decomposition of the observed changes in $G_{F I}$

\begin{tabular}{llll}
\hline & Absolute change in the Gini coeff. $(\Delta G)$ & SE & CE \\
\hline FI (2014-2015) & -0.040 & 0.016 & -0.062 \\
\hline
\end{tabular}


However, it is clear that such an impact is due not only to changes in policy but also to market dynamics. The first aspect can be attributed to the external convergence process that decreased the Italian budget for DPs as well as to the national decision to activate VCS (that is, a highly concentrated payment) instead of redistributive payments or payments for areas with natural constraints (which could have further hindered farm income inequality). In terms of the market, other explanations include the increasing pressures of volatility due to climate change and globalization that expose farmers to increasing income risks (Knapp and Loughrey 2017).

Concerning H3 (the application of the tunnel model in Italy, compared to the flat rate, limits the redistribution of the DPs and their equalizing effect on farm income), Table 7 compares the effect of the two alternative internal convergence models (that is, tunnel model and flat rate) on the redistribution of DPs. What emerges is that the

Table 7 Gini decomposition of total income. Static analyses (2015 vs 2019 flat rate vs 2019 tunnel model)

\begin{tabular}{|c|c|c|c|c|c|c|}
\hline & $G_{k}$ & $R_{k}$ & $S_{k}$ & $C_{k}$ & $P_{k}$ & $\eta$ \\
\hline \multicolumn{7}{|c|}{2015 ("tunnel" model_partial convergence) } \\
\hline $\mathrm{Fl}$ & 0.778 & 1.000 & 1.000 & 0.778 & 1.000 & 0.000 \\
\hline Ml & 0.798 & 0.997 & 0.935 & 0.796 & 0.957 & 0.022 \\
\hline VCS & 0.862 & 0.680 & 0.006 & 0.586 & 0.005 & -0.002 \\
\hline $\mathrm{BPS}+\mathrm{SFS}+\mathrm{GR}+\mathrm{YFP}$ & 0.711 & 0.710 & 0.058 & 0.505 & 0.038 & -0.020 \\
\hline \multicolumn{7}{|l|}{ of which: } \\
\hline BPS & 0.716 & 0.705 & 0.039 & 0.505 & 0.026 & -0.014 \\
\hline SFS & 0.979 & -0.503 & 0.000 & -0.493 & 0.000 & 0.000 \\
\hline GR & 0.721 & 0.705 & 0.019 & 0.509 & 0.012 & -0.006 \\
\hline YFP & 0.995 & 0.525 & 0.000 & 0.522 & 0.000 & 0.000 \\
\hline \multicolumn{7}{|c|}{2019 ("tunnel" model_partial convergence) } \\
\hline $\mathrm{Fl}$ & 0.778 & 1.000 & 1.000 & 0.778 & 1.000 & 0.000 \\
\hline $\mathrm{Ml}$ & 0.800 & 0.998 & 0.938 & 0.799 & 0.964 & 0.025 \\
\hline VCS & 0.862 & 0.680 & 0.006 & 0.586 & 0.005 & -0.002 \\
\hline $\mathrm{BPS}+\mathrm{SFS}+\mathrm{GR}+\mathrm{YFP}$ & 0.646 & 0.685 & 0.055 & 0.443 & 0.032 & -0.024 \\
\hline \multicolumn{7}{|l|}{ of which: } \\
\hline BPS & 0.649 & 0.684 & 0.037 & 0.444 & 0.021 & -0.016 \\
\hline SFS & 0.979 & -0.503 & 0.000 & -0.493 & 0.000 & 0.000 \\
\hline GR & 0.649 & 0.684 & 0.018 & 0.444 & 0.010 & -0.008 \\
\hline YFP & 0.995 & 0.572 & 0.000 & 0.569 & 0.000 & 0.000 \\
\hline \multicolumn{7}{|l|}{2019 (flat rate) } \\
\hline $\mathrm{Fl}$ & 0.778 & 1.000 & 1.000 & 0.778 & 1.000 & 0.000 \\
\hline $\mathrm{Ml}$ & 0.805 & 0.998 & 0.935 & 0.804 & 0.967 & 0.031 \\
\hline VCS & 0.862 & 0.680 & 0.006 & 0.586 & 0.005 & -0.002 \\
\hline $\mathrm{BPS}+\mathrm{SFS}+\mathrm{GR}+\mathrm{YFP}$ & 0.614 & 0.615 & 0.058 & 0.378 & 0.028 & -0.030 \\
\hline \multicolumn{7}{|l|}{ of which: } \\
\hline BPS & 0.616 & 0.617 & 0.039 & 0.380 & 0.019 & -0.020 \\
\hline SFS & 0.979 & -0.503 & 0.000 & -0.493 & 0.000 & 0.000 \\
\hline $\mathrm{GR}$ & 0.616 & 0.617 & 0.019 & 0.380 & 0.009 & -0.010 \\
\hline YFP & 0.994 & 0.415 & 0.000 & 0.413 & 0.000 & 0.000 \\
\hline
\end{tabular}


implementation of the tunnel model in Italy limits the equal allocation of DPs more than the flat rate even though the tunnel model favors a certain redistribution of DPs. This effect depends on the fact that the tunnel model maintains a somewhat enduring relationship with the old SPS, which rewarded sectors and farms with a high level of farm income. In this regard, the application of the tunnel model instead of the flat rate reduces the ability of the CAP to counter the concentration of DPs and to more equally support farm incomes.

Lastly, the outcomes of the dynamic analyses clearly reveal that CAP reform in Italy is expected to decrease the concentration of DPs (Table 8), even though the implementation of the tunnel model instead of the flat rate for the 2015-2019 period limits the potential equalizing effect of payments.

\section{Conclusions}

The study presents an analysis of the redistributive effects of the direct payments introduced by the CAP 2013 reform in Italy. The decomposition of G allowed us to analyze the evolution of the farm income and direct payment distribution over the 2015-2019 period, and the empirical results confirmed that the concentration of farm income in Italy is high. However, DPs reduce farm inequality even though they are also highly concentrated. In sum, DPs equalize income because (i) they are less correlated with income levels than income sources that are more market-driven, and (ii) on average, DPs represent a significant share (approximately 10\%, including farms that do not benefit from DPs) of the farm income.

However, the main focus of this paper was the redistributive effect of the new direct payment scheme introduced by the CAP 2013 reform that replaced the former SPS in Italy, where approximately $90 \%$ of the national ceiling was devoted to the BPS and the GR. Both static and dynamic analyses highlighted an expected decrease in the concentration of direct payments by 2019 because Italy will progressively shift from the "historical" regional model to a tunnel model for internal convergence during the transitional 2015-2020 period. Conversely, the decrease in the DP/FI ratio between 2014 and 2019 due to both policy changes and exogenous factors is expected to negatively affect the ability of these payments to oppose the regressive effect of MIs, particularly for regions and sectors that mainly benefitted from the SPS introduced by CAP 2003 reform. In more detail, the results indirectly highlight that the more farm income is affected by changing market conditions (increasingly influenced by price volatility) related to output composition (consumption, investment, government expenditure, and gross exports and imports), the more unequally it is distributed. This phenomenon is affected by any increase (decrease) in the budget for DPs, which could

Table 8 Dynamic analyses: decomposition of the observed changes in $G_{D P s}$

\begin{tabular}{llll}
\hline & Absolute change in the Gini coeff. $(\Delta G)$ & SE & CE \\
\hline DPs (2015 TM-2019 FR) & -0.091 & 0.000 & -0.091 \\
DPs (2015 TM-2019 TM) & -0.058 & -0.003 & -0.059 \\
DPs (2014-2019 FR) & -0.105 & -0.006 & -0.105 \\
DPs (2014-2019 TM) & -0.072 & -0.009 & -0.072 \\
DPs (2019 FR-2019 TM) & 0.033 & -0.003 & 0.032 \\
\hline
\end{tabular}


improve (worsen) the stabilization and redistribution of farm income and reduce (increase) its concentration since such aid tends to equalize farm income.

In terms of policy implications, the present study suggests that the decision to opt for a partial convergence model (instead of a flat rate model) as well as for degressivity and capping mechanisms (instead of activating the redistributive payment) has somewhat limited the redistributive effect of direct payments in Italy. In this regard, recent evidence confirms that the impact of the application of these specific redistributive tools (such as degressivity and capping) in Italy is limited. On the other hand, if Italy had used the same amount of public resources used for the voluntary couple support (which is concentrated in the upper decile of the population by farm income) for the redistributive payments and/or for the payments for mountain areas, it is likely that a more equitable distribution of DPs could have been obtained.

Overall, the linkage between land and direct payments is always present in the background and strongly affects the correlation with farm income level and the redistributive effect of these types of aid. Moreover, especially in case of the flat rate, it exacerbates the transfer of public income support to land prices, reducing the effectiveness of the redistributive role of direct payments. Therefore, to obtain a better redistribution of payments, testing alternative parameters for allocating direct payments that substitute for or are combined with the current parameter (land) could be more effective than continuing to focus attention on redistributive tools/mechanisms (flat rate models, external convergence, degressivity, capping) or payments that can only reduce, but not eliminate, redistributive distortions caused by the connection between land and direct payments.

However, exogenous factors also hinder the equalizing action of direct payments in Italy since in the context of greater market orientation of the CAP, increased market exposure leads to higher risks of price volatility and increasing pressure on incomes. This scenario causes the share of farm income from the market that is unequally redistributed to sharply increase, which is further worsened by the external convergence process of DPs (which has strongly penalized Italy), and the reduction in the EU budget has even limited the ability of DPs to reduce income inequality. Against this backdrop, risk management instruments that combine EU-level interventions with the strategies of the MSs as well as private sector instruments that address income stability could be helpful in enhancing farm incomes.

Lastly, the present paper allows avenues for future research in this field to be outlined. Such research may involve quantitative analyses aimed at evaluating the redistributive effect of direct payments and the impacts on concentration with particular attention to the territorial and sectoral impacts. Attention should be paid to the comparisons of different scenarios characterized by the application of alternative (i) criteria for both internal and external convergence of direct payments, (ii) redistributive mechanisms/tools (degressivity, capping), and (iii) targeted payments focused on redistributive objectives.

\section{Endnotes}

${ }^{1}$ It must be noted that although the CAP reform officially came into force in 2014, the new direct payment scheme began in 2015 due to some delays in the European decision-making process. 
${ }^{2}$ Regulation (EU) no. 1307/2013 of the European Parliament and of the Council of 17 December 2013 establishing rules for direct payments to farmers under support schemes within the framework of the CAP and repealing Council Regulation (EC) no. 637/2008 and Council Regulation (EC) no. 73/2009.

${ }^{3}$ Keeney (2000) and Mishra et al. (2009) noted that with a substantial incidence of negative incomes, $G(Y)$ may become overstated, perhaps causing values greater than 1 . However, the decomposition procedure remains applicable as long as the average value of all income sources is positive (Pyatt et al. 1980).

${ }^{4}$ Both samples also include farms that do not benefit from any CAP aid.

${ }^{5}$ Creative Commons license CC BY-NC-SA 4.0: http://creativecommons.org/licenses/ by-nc-sa/4.0/legalcode

${ }^{6}$ In Italy, degressivity is applied since the voluntary redistributive payments have not been implemented. To generate a more equitable distribution of direct payments, a mandatory reduction in BPS by $50 \%$ for the part exceeding $150,000 €$ is introduced. Moreover, this percentage is $100 \%$ for the part exceeding $500,000 €$, thereby introducing a de facto "capping" on BPS. In Italy, such a reduction is applied after deducting labor costs for the previous year, i.e., salaries to employees as well as taxes paid and social welfare contributions, from the basic payment.

${ }^{7}$ In this regard, it must be noted that, in contrast to previous research on the same topic, the DP/FI ratio is calculated for the whole FADN sample and thus also considers farms that do not receive any DPs.

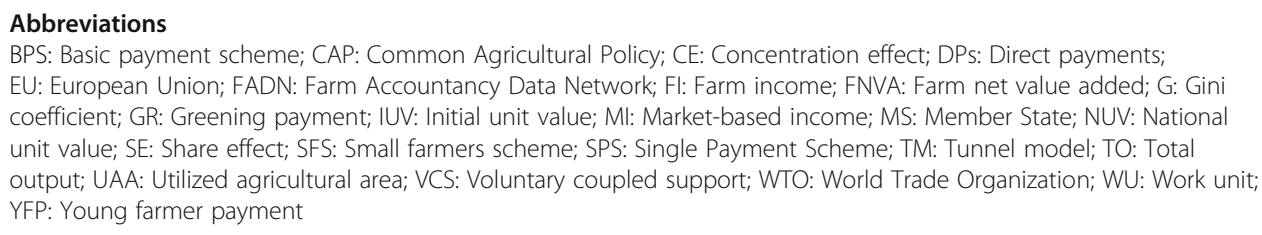

Acknowledgements

The authors acknowledge the Council for Agricultural Research and Agricultural Economics Analysis (CREA) for providing access to the Italian FADN database.

\section{Authors' contributions}

The paper design was conceived by the SC. He wrote the Introduction, the Literature review, the Policy framework, and the Conclusions, together with AF. SC also carried out the data collection and the quantitative analysis, and he was responsible of the methodological section as well as of the Results and discussion section. Both authors read and approved the final manuscript.

Ethics approval and consent to participate

Not applicable

Consent for publication

Not applicable

Competing interests

The authors declare that they have no competing interests.

\section{Publisher's Note}

Springer Nature remains neutral with regard to jurisdictional claims in published maps and institutional affiliations.

Received: 22 November 2017 Accepted: 20 September 2018

Published online: 10 October 2018

References

Allanson P (2006) The redistributive effects of agricultural policy on Scottish farm incomes. J Agric Econ 57(1):117-128. https://doi.org/10.1111/j.1477-9552.2006.00035.x. 
Allanson P, Rocchi B (2008) A comparative analysis of the redistributive effects of agricultural policy in Tuscany and Scotland. Rev Agric Environ Stud 89:35-56.

Ciaian P, Kancs d A', Espinosa M (2017) The impact of the 2013 CAP reform on the decoupled payments' capitalisation into land values. J Agric Econ 69(2):306-37. https://doi.org/10.1111/1477-9552.1225.

Ciliberti S, Frascarelli A (2015) A critical assessment of the implementation of CAP 2015-2020 direct payments in Italy. Biobased Appl Econ 4(3):261-277. https://doi.org/10.13128/BAE-16377.

De Gocht A, Britz W, Ciaian P, G y PS (2013) Farm type effects of an EU-wide direct payment harmonisation. J Agric Econ 64: 1-32. https://doi.org/10.1111/1477-9552.12005.

El Benni N, Finger R (2012) The effect of agricultural policy reforms on income inequality in Swiss agriculture - an analysis for valley, hill and mountain regions. J Policy Model 35(4):638-651. https://doi.org/10.1016/j.jpolmod.2012.03.005.

Erjavec E, Chantreuil F, Hanrahan K, Donnellan T, Salputra G, Kožar M, van Leeuwen M (2011) Policy assessment of an EU wide flat area CAP payments system. Econ Model 28:1550-1558. https://doi.org/10.1016/j.econmod.2011.02.007.

European Commission (2006) Scenar 2020 - scenario study on agriculture and the rural world. Office for Official Publications of the European Communities, Luxembourg.

European Commission (2009). Scenar 2020 II - update for analysis of prospects in the Scenar 2020 study. Preparing for change.

European Commission (2010) Farm accountancy data network: an A to Z of methodology. Available via http://ec.europa.eu/ agriculture/rica/pdf/site_en.pdf Accessed 5 Jul 2017.

European Commission (2011) Common agricultural policy towards 2020 - assessment of alternative policy options, Brussels, p. 1-85. 20.10.2011SEC(2011)1153final/2.

European Commission (2017). Report on the distribution of direct payments to agricultural producers (financial year 2016).

Findeis JL, Reddy VK (1987) Decomposition of income distribution among farm families. North Eastern J Agric Econ 16:165-173.

Grant W (2010) Policy instruments in the common agricultural policy. West Eur Policy 33:22-38. https://doi.org/10.1080/ 01402380903354049

Howley P (2016) Subsidy streams versus a CAP bond: an assessment of farmers' preferences. Land Use Policy 51:182-190. https://doi.org/10.1016/j.landusepol.2015.11.007.

Huang H, Legg W, Cattaneo A (2010) Climate change in agriculture: the policy challenge for the 21st century. EuroChoices 9: 505-526. https://doi.org/10.1111/j.1746-692X.2010.00174.x.

Keeney M (2000) The distributional impact of direct payments on Irish farm incomes. J Agric Econ 51(2):252-263. https://doi. org/10.1111/j.1477-9552.2000.tb01227.x.

Klaiber AH, Salhofer K, Thompson SR (2017) Capitalisation of the SPS into agricultural land rental prices under harmonisation of payments. J Agric Econ 68:710-726. https://doi.org/10.1111/1477-9552.12207.

Knapp E, Loughrey J (2017) The single farm payment and income risk in Irish farms 2005-2013. Agric Food Econ 5(1):1-15. https://doi.org/10.1186/s40100-017-0078-9.

Lerman RJ, Yitzhaki S (1985) Income inequality effects by income source: a new approach and applications to the U.S. Rev Econ Stat 67:151-156. https://doi.org/10.2307/1928447.

Mishra AK, El-Osta HS, Gillespie JM (2009) Effect on agricultural policy on regional income inequality among farm households. J Policy Model 31:325-340. https://doi.org/10.1016/j.jpolmod.2008.12.007.

Mishra AK, Paudel KP (2011) Estimating permanent income and wealth of the US farm households. J Appl Econ 43:15211533 https://doi.org/10.1080/00036840802600582.

Moro D, Sckokai P (2013) The impact of decoupled payments on farm choices: conceptual and methodological challenges. Food Policy 41:28-38. https://doi.org/10.1016/j.foodpol.2013.04.001.

Podder N, Chatterjee S (1998) Sharing the national cake in post reform New Zealand: income inequality trends in terms of income sources. J Public Econ 86:1-27.

Pyatt G, Chen C, Fei J (1980) The distribution of income by factor components. Q J Econ 95:451-473.

Rizov M, Pokrivcak J, Caian P (2013) CAP subsidies and productivity of the EU farms. J Agric Econ 64:537-557. https://doi.org/ 10.1111/1477-9552.12030.

Rocchi B, Romano D, Stefani G (2005) Distributive impacts of alternative agricultural policies: A SAM-based analysis for Italy. Cahiers d'Economie et de Sociologie Rurales, INRA Editions, 77:85-112. Available via https://hal.archives-ouvertes.fr/hal01201114/document Accessed 8 Jul 2017.

Schmid E, Sinabell F, Hofreither MF (2006) Distributional effects of CAP instruments on farm household incomes. Paper presented at the American Agricultural Economists Association Annual Meeting, Long Beach 23-26 July, 2006.

Severini S, Tantari A (2013a) The effect of the EU farm payments policy and its recent reform on farm income inequality. J Policy Model 35:212-227. https://doi.org/10.1016/j.jpolmod.2012.12.002.

Severini S, Tantari A (2013b) The impact of agricultural policy on farm income concentration: the case of regional implementation of the CAP direct payments in Italy. Agric Econ 44:275-286. https://doi.org/10.1111/agec.12010.

Severini S, Tantari A (2015) The distributional impact of agricultural policy tools on Italian farm households incomes. J Policy Model 37(1):124-135.

Severini S, Tantari A, Di Tommaso G (2016) Do CAP direct payments stabilise farm income? Empirical evidences from a constant sample of Italian farms. Agric Food Econ 4(6):1-17. https://doi.org/10.1186/s40100-016-0050-0.

Sinabell F, Schmid E, Hofreither MF (2013) Exploring the distribution of direct payments of the common agricultural policy. Empirica 40(2):325-341. https://doi.org/10.1016/j.jpolmod.2015.01.004

van Ittersum MK, Ewerta F, Heckelei T, Wery J, Olsson JA, Andersen E, Bezlepkina I, Brouwer F, Donatelli M, Flichman G, Olsson L, Rizzoli AE, van der Wal T, Wien JE, Wolf J (2008) Integrated assessment of agricultural systems - a component-based framework for the European Union (SEAMLESS). Agric Syst 96(3):150-165. https://doi.org/10.1016/j.agsy.2007.07.009.

Westhoek HJ, Overmars KP, van Zeitjs $\mathrm{H}$ (2013) The provision of public goods by agriculture: critical questions for effective and efficient policy making. Environ Sci Pol 32:5-13. https://doi.org/10.1016/j.envsci.2012.06.015.

Von Witze H, Noleppa S (2007) Agricultural and trade policy reform and inequality: the distributive effects of direct payments to German farmers under the EU's new common agricultural policy. Working paper 79, Humboldt University, Berlin. 